\section{A filosofia de Platão e o debate bioético sobre o fim da vida: interseções no campo da Saúde Pública}

\author{
Plato's philosophy and the bioethical debate \\ on the end of life: intersections in Public Health
}

Rodrigo Siqueira-Batista 1,2,3 Fermin Roland Schramm 2,4

\author{
1 Núcleo de Estudos em \\ Filosofia e Saúde, Fundação \\ Educacional Serra dos \\ Órgãos, Teresópolis, Brasil. \\ 2 Departamento de Ciências \\ Sociais, Escola Nacional \\ de Saúde Pública, \\ Fundação Oswaldo Cruz, \\ Rio de Janeiro, Brasil. \\ 3 Comissão de Bioética, \\ Hospital Universitário \\ Clementino Fraga Filho, \\ Universidade Federal \\ do Rio de Janeiro, \\ Rio de Janeiro, Brasil. \\ 4 Instituto Nacional do \\ Câncer, (INCA), Ministério \\ da Saúde-Brasil. \\ Correspondência \\ Rodrigo Siqueira-Batista \\ Av. Alberto Torres 111, \\ Teresópolis, $R J$ \\ 25964-000, Brasil. \\ anaximandro@hotmail.com
}

\section{Abstract}

This article discusses bioethical aspects of medical futility, focusing on some of its intersections in public health. Starting from a demarcation of finitude in the core of the philosophical and bioethical debate on the end of life, we confront the contemporary criticism regarding medical futility with the ideas of Plato (427-347 B.C.), a philosopher who proposed significant considerations on numerous features of the medicine of his time. We thus explore novel theoretic references to guide the disputes related to this essential problem, the implications of which are decisive to health and life.

Bioethics; Medical Futility; Death; Public Health

\section{Introdução}

A morte é um dos mais genuínos problemas da condição humana, tendo demandado esforços para o seu equacionamento ao longo da História do pensamento ocidental 1 . Ainda antes do nascimento da filosofia - ocorrido por volta do século VI a.C. - já podiam ser percebidos matizes relativos à finitude, como o referido em versos da Ilíada e da Odisséia 2,3.

Um mote tão arcaico foi capaz de perpassar a cultura no Ocidente, influenciando decisivamente suas mais díspares faces, como o mito, a filosofia, a ciência e a arte 4 . Do ponto de vista filosófico, diferentes autores trataram do significado da morte: pensadores como Michel de Montaigne - para o qual filosofar é aprender a morrer 5 - e Martin Heidegger - que viu no homem mortal aquele que é capaz de olhar em direção ao divino 6 - afirmam a finitude como instância inalienável à dimensão humana; por outro lado, filósofos como Baruch Spinosa - o qual, em sua Ética, veda à filosofia a possibilidade de uma vocação para pensar no passamento 7 - e G. W. F. Hegel que, em sua Fenomenologia do Espírito 8, articula um poderoso discurso com vistas à superação da morte, negam a primazia da finitude como questão primeva da existência humana. Mesmo que haja uma impossibilidade consubstancial para a reflexão sobre o próprio fim, o saber-se mortal é um dos esteios da experiência que o homem tem de si 
mesmo ${ }^{1}$. Assim pois tal temática, que pode ser considerada visceral à filosofia, ganhou diferentes contornos na segunda metade do século $\mathrm{XX}$, graças à inserção de novos elementos no panorama espiritual, podendo-se mencionar: (1) a "crise" da razão experimentada sobretudo no período pós-guerra, com as influências do existencialismo de Jean-Paul Sartre 9 e o niilismo - cujas raízes podem ser encontradas já em Friedrich Nietszche $10-$, (2) as novas possibilidades de atuação terapêutica da medicina, conseqüentes aos "avanços" obtidos pela biotecnociência 11 - e (3) a emergência de uma "nova" disciplina, a Bioética 12.

O termo bioética foi alcunhado pelo oncologista Van Rensslaer Potter em 1970 13,14, ao se referir à deterioração das interações no binômio homem-natureza, em uma conotação marcadamente ecológica. Na concepção de Potter, o ser humano se portaria como um câncer para a natureza, possuindo uma ação extremamente deletéria sobre esta última. A necessidade de rever esta atitude, sob pena de extinção da vida no planeta, encontra-se nas raízes do nascente campo do saber, configurando-se um sentido de ciência da sobrevivência. Dessa feita, a bioética poderia ser vista como uma nova ética científica, cujos objetivos primevos seriam garantir a perpetuação da espécie humana e sua qualidade de vida - a partir da preservação da biosfera -, a resolução de problemas sanitários e a construção de uma biologia capaz de estender seus horizontes para a indagação de normas e valores, indo além do seu repertório descritivo tradicional 15,16. Sem embargo, alguns desdobramentos evolutivos para esse neologismo incluíram ética da vida, ética da qualidade de vida, ética biomédica e ética aplicada ao campo da biomedicina e da saúde, originando problemas referentes à extensão de seu campo semântico: "(a) algumas [definições] são demasiado abrangentes, como 'ética da vida', que deixa entender que toda ética é necessariamente uma bioética, o que é falso se entendermos a bioética num sentido estrito e não lato; (b) outras demasiado restritas, como 'ética biomédica', que na prática acaba se confundindo com a ética médica tradicionalmente entendida e esquece a reconfiguração da ética acontecida com o surgimento das éticas aplicadas e a bioética graças às novas interrogações sobre os processos do viver, adoecer e morrer, que emergem com os avanços da biomedicina e a emergente sociedade de 'consumidores"' 17 (p. 26).

A intensificação dos debates sobre a natureza da bioética acabou por imputar profundas transformações em relação ao conceito inicialmente proposto, podendo ser atualmente com- preendida como: (1) uma ética aplicada aos problemas levantados pelas ciências da saúde e da vida; (2) um genuíno movimento cultural, cujos aspectos de maior relevância incluem a secularização difusa, o acentuado pluralismo e a grande valorização da autonomia individual 12, ou ainda, preferencialmente, em concordância ao formulado por Miguel Kottow 18; (3) como a disciplina que se refere à moralidade dos atos humanos que podem alterar, de forma irreversível, os processos, também irreversíveis, dos sistemas vivos. Esta última concepção tem como vantagens ser simultaneamente ampla e suficientemente precisa, por não restringir a bioética ao âmbito biomédico - permitindo a inclusão de aspectos como o trato com os animais, as práticas que envolvem o uso de biotecnologias e as intervenções sobre o meio ambiente - além de não olvidar o quesito irreversibilidade em sua estreita correlação com o saber-fazer constituído pela vigência do paradigma biotecnocientífico e suas aplicações biotecnológicas 17.

Independentemente da delimitação que se forneça ao campo de estudo da bioética, é mister que esta seja reconhecida, por um lado, como disciplina afim à filosofia possuindo, assim, uma metodologia própria, consistente em utilizar uma série de "ferramentas" conceituais, como o rigor terminológico em relação aos termos e princípios empregados, a textura lógica do discurso e a sua força argumentativa - herança da tradição analítica; e, por outro lado, como uma possível reconfiguração multi e interdisciplinar de temas e problemas que implicariam a cooperação de disciplinas não estritamente filosóficas.

Entretanto, aqui será adotado o ponto de vista que considera a bioética como âmbito pertencente, de direito, à própria filosofia; em particular, à filosofia moral, pois isso parece mais adequado para poder dar conta da dupla atividade - ao mesmo tempo descritiva e normativa - da bioética, quando aplicada aos conflitos de interesses e valores, o que pressupõe o manejo de diferentes formas de se pensar o problema em pauta - no caso, o termo da existência - promovendo a adequada formulação das questões.

No amplo horizonte representado pela bioética, uma das frentes de debate é precisamente o fim da vida, ganhando força as discussões sobre eutanásia, distanásia, até onde intervir sem agredir, o que, em um primeiro momento, parece apontar para uma preeminência dos aspectos individuais - foco naquele que morre -, em detrimento das perspectivas que levam em consideração a sociedade. Entretanto, o ques- 
tionamento dessa visão é uma das dimensões tomadas pela bioética na problematização da morte, sendo importante a seguinte demarcação: a abrangência das discussões perpassa não somente os pontos relativos ao indivíduo como no caso das decisões terapêuticas em unidades de terapia intensiva - mas também as situações em que entram em jogo aspectos cruciais concernentes às populações - como na distribuição de recursos em saúde, no contexto de uma sociedade - como a brasileira -, que está "envelhecendo" rapidamente. Este aspecto tem marcada relevância, uma vez que a alocação de recursos no setor público de saúde utiliza como importante critério a distribuição dos bens sociais de acordo com considerações sociais e políticas, devendo o Estado assumir tal gerência, definindo as prioridades e os modos para a sua correta utilização 19,20,21. No que se refere à realidade no Brasil, é importante explicitar que o aumento da expectativa de vida tem permitido que um maior número de pessoas esteja sujeita ao adoecimento por enfermidades crônico-degenerativas, o que implica muitas vezes em um processo de morrer mais prolongado e mais correlacionável à assistência médica especializada, internação hospitalar de longa duração e emprego de aparato tecnológico de alto custo para manutenção da vida. Esse conjunto de fatores delimita, destarte, uma inquestionável interface do fim da vida com a saúde pública.

O panorama encontra-se assim montado: há um problema central da vida - a morte -, o qual vem sendo matizado em novas nuanças entre as quais a da bioética, albergando uma infrene e intrínseca necessidade de estimular as discussões - com uma série de possíveis interseções no âmbito da saúde pública, como nos aspectos relativos à justiça como eqüidade e à alocação de recursos 21,22. Apesar da inegável atualidade deste contexto, alguns pontos do maior interesse para a discussão podem ser recolocados, em uma lídima atitude filosófica, a partir dos referenciais teóricos de um período tão longínquo quanto o século IV a.C. - a filosofia de Platão -, obviamente sem procurar o estabelecimento de uma linha de continuidade entre um e outro momento, o que seria, no mínimo, ingênuo. Em que medida a(s) pergun$\mathrm{ta}(\mathrm{s})$ formulada(s) por um pensador da Antigüidade poderia $(\mathrm{m})$ contribuir para o debate bioético sobre o fim da vida, uma temática que se mostra um "fruto" tão contemporâneo? Percorrer o caminho em busca desta resposta é, precisamente, o escopo do presente artigo.

\section{O debate bioético sobre o fim da vida: interseções com a saúde pública}

Intimamente relacionada à morte está a questão do processo de morrer, o qual evoca indagações relativas ao sofrimento e à qualidade de vida 23 . Falecer ganha contornos de "partida", implica o deixar de fazer parte deste único mundo conhecido, afastando-se do convívio de pessoas queridas. Morrer causa temor, é o desconhecido que está por vir, situando o homem diante de seu próprio ocaso, relação esta chamada por M. Heidegger de Sein zum Tode, ou seja, ser-para-a-morte 6 . Se à vida pode-se atribuir a afirmação do ser, sua positividade, o ocaso institui o não-ser, o limite do que não pode ser reconhecido, sequer pensado, como o demarcado por Françoise Dastur: "de Aristóteles a Hegel, essa negatividade absoluta, essa ruptura radical, esse impensável puro e simples que é a morte se vêem convertidos em 'não-ser relativo' e 'negatividade determinada', em ruptura 'substituível' e em simples limite do que pode ser pensado: o que, no final das contas, testemunha a incapacidade metafísica de enfrentar verdadeiramente a morte" 1 (p. 56).

Se esse não-ser está para além do que pode ser verdadeiramente pensado, o mesmo não se aplicaria ao processo de morrer, o qual está muitas vezes relacionado, no âmbito das inquietações humanas, à idéia do sofrimento imposto por uma doença grave e mitigante. Nesta situação, a perspectiva de extinção da vida de forma insidiosa, possibilita a adoção de uma postura reflexiva, com revisão de conceitos e paradigmas por parte daqueles que experimentam a proximidade da morte - quer enfermos, familiares, ou profissionais.

Esta árida realidade é também perceptível na atuação do médico diante do paciente que morre 24 . É realmente difícil se lidar com a idéia de morte 8 - e com seu processo -, o qual pode conter um sem número de aspectos dolorosos. Não seria diferente entre os médicos e demais profissionais de saúde. Torna-se, posto isso, necessário refletir sobre o processo - afinal, ele é inerente à prática médica -, postar-se adequadamente, quando ele estiver em curso, e poder falar sobre ele com o enfermo que morre. A própria tessitura arquetípica da mitologia traz luz sobre essa questão se, por exemplo, é lembrada a narrativa sobre Asclépio, o deus grego filho de Febo Apolo, que no seu aprendizado com o centauro Quíron teria adquirido a habilidade de ressuscitar os mortos; ou seja, há uma perspectiva segundo a qual o deus da medicina, aquele que deveria cuidar e, às vezes, curar, almeja - e eventualmente consegue - de- 
ter a morte, vencendo-a. É interessante perceber no mito, o já implícito desejo de sobrepujar a finitude, muitas vezes tão inerente à postura médica, mesmo nos dias de hoje 25 . Esta problemática atitude é fruto, muito provavelmente, da ferida narcísica evocada por uma ingênua prepotência em relação ao binômio vidamorte 26 , algo que se inicia ainda nos primeiros anos do curso médico. No entanto, imaginar que a medicina consista apenas em um "combate" à morte pode gerar estes e outros conflitos no médico que assiste ao doente, sendo mencionável a amarga sensação de impotência diante de um mal incurável 27 .

Exatamente na confluência entre a percepção médica sobre o processo de morrer e as questões levantadas pela biotecnociência estão colocados pontos que representam o coração do debate 28: a obstinação terapêutica - distanásia-, a eutanásia e o suicídio assistido. Veja-se um pouco mais de perto o fulcro destas questões.

A aplicação de novas tecnologias à medicina trouxe em seu âmago todo um repertório de manutenção das funções biológicas, com amplas possibilidades para salvar um sem número de vidas. Neste âmbito, um dos elementos de destaque é a biotecnociência, capaz de ir ao encontro do "velho" desejo humano de vencer a morte. A aplicação irresponsável desta última situa-se no âmago da postura adotada por alguns médicos de manter artificialmente o enfermo moribundo com os sistemas orgânicos em funcionamento, por meio do emprego de toda a ciência e tecnologia disponíveis, com a obtenção de uma nova "vitória" sobre a morte a cada momento, a despeito de todo o sofrimento causado. Sobre isso exatamente se assenta o conceito de distanásia $(\delta ı \varsigma=$ dificulda-

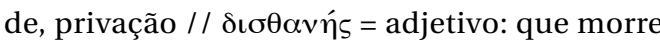
duas vezes; no latim, dis dá idéia de separação e negação), palavra inicialmente proposta por Morcache, em 1904, que pode ser entendida como a manutenção da vida por meio de tratamentos desproporcionais - ou seja, como sinônimo de obstinação terapêutica - levando a um processo de morrer prolongado e com sofrimento físico ou psicológico 29.

Colocando-se em posição diametralmente oposta à obstinação terapêutica está a eutanásia, termo originário do grego que pode ser traduzido como boa morte $-\varepsilon v=\mathrm{adv}$. bem $/ /$ regular, justamente // com bondade, com benevolência // felizmente; $\theta$ áv $\alpha$ os = morte - e que acabou por ganhar enorme relevância no debate ético do fim da vida: o vocábulo tem "raízes” ainda na Antigüidade, tendo sido inicialmente utilizado por Suetônio, no século II d.C., para descrever a morte "suave" do imperador Augusto 30. Conceito relacionado à eutanásia, o suicídio assistido é descrito quando uma pessoa gravemente acometida por uma moléstia incurável, sendo incapaz de tornar fato sua disposição de morrer, solicita o auxílio de outra. Neste último caso o enfermo está sempre consciente, manifestando claramente sua opção pela morte - na eutanásia nem sempre o doente encontra-se cônscio, como no caso de um paciente terminal e em coma que está sendo mantido vivo em um ventilador mecânico, o qual é desligado, ocasionando a morte. Com base nessas conjecturas, poderia se diferenciar os seguintes “tipos” de eutanásia:

- Quanto ao ato em si 31: a eutanásia ativa conduta deliberada de provocar a morte sem sofrimento do paciente, por fins humanitários (p. ex., utilização de uma injeção letal) -, a eutanásia passiva - quando a morte ocorre por omissão em se iniciar uma ação médica (p. ex., deixar de se acoplar um paciente em insuficiência respiratória ao ventilador artificial) - e $e u$ tanásia de duplo efeito - quando a morte é acelerada como conseqüência de ações médicas não visando ao êxito letal, mas sim o alívio do sofrimento de um paciente (p. ex., emprego de uma dose de morfina para dor que gera, secundariamente, depressão respiratória e o óbito).

- Quanto ao consentimento do paciente 32: a eutanásia voluntária - a qual atende uma vontade expressa do doente, sendo, portanto, um sinônimo do suicídio assistido -, eutanásia involuntária - quando o ato é realizado contra a vontade do enfermo (o que é sinônimo de homicídio) - e eutanásia não voluntária - quando a morte é levada a cabo sem que se conheça a vontade do paciente.

Há problemas em ambos os conceitos - distanásia e eutanásia. Enquanto o primeiro é pouco conhecido entre os profissionais de saúde - ainda que muito praticado nas UTIs -, a palavra eutanásia possui uma intensa polissemia, o que promove inúmeros equívocos 33 . Um exemplo é a confusão de conceitos como eutanásia e ortotanásia, este último um termo impreciso que significaria a morte no seu tempo certo, sem os tratamentos desproporcionais distanásia - e sem abreviação do processo de morrer-eutanásia 34; o difícil, neste caso, é caracterizar o que seria esse "tempo certo". Ademais, há também confusão com termos como homicídio por piedade e suicídio, o que acaba por propiciar um caráter pejorativo à palavra, trazendo grande prejuízo ao debate.

Estabelecidas estas colocações acerca da terminologia, põe-se em discussão alguns aspectos de interseção entre a bioética do fim da 
vida e a saúde coletiva. As UTIs - chamadas de as modernas catedrais do sofrimento humano 33 - vêm albergando, cada vez mais, elevadas tecnologia e complexidade, implicando gastos de grande magnitude. Se é compreendido que os recursos para alocação na saúde não são infinitos, surge o problema de como melhor aplicá-los para esta finalidade - manutenção da vida - sem detrimento para outras ações tradicionalmente de grande relevância em saúde pública - por exemplo, a vacinação. Uma boa forma de trazer luz sobre essa questão é a distinção de três níveis de alocação de recursos proposta por Miguel Kottow 18: uma macrodistribuição, a qual se define pelo critério das disponibilidades, o conceito de proteção sanitária e o direito à atenção médica; uma mesodistribução, que se pauta na aplicação de critérios sociais para dispor o orçamento sanitário nacional entre os diferentes grupos que compõem a sociedade; e uma microdistribuição, que se concretiza no ato médico individualizado, abarcando os referenciais de planejamento dos recursos humanos e técnicos. As três instâncias têm dominância sobre a interseção saúde pública-bioética do fim da vida, mas é sobretudo em relação à microdistribuição que recai a maior parte do problema, uma vez que até $75 \%$ dos gastos com saúde referem-se a este nível, com implicações no mínimo trágicas na gestão, na medida em que necessidades irrefutáveis eventualmente deixam de ser contempladas.

Outro ponto a ser mencionado refere-se à limitação evidenciada nos discursos sobre a justiça, desde que se pretendam universalmente aplicáveis 20,22. A justiça sanitária em um país como o Brasil - cuja população é constituída por grande contingente de pobres e miseráveis - não pode partir dos mesmos pressupostos empregados nas nações do primeiro mundo. Torna-se, pois, necessário um conceito mais exeqüível - ou factível - para a realidade latino-americana, como o proposto por Kottow: "uma possível definição que encarna uma ordem justa e que contempla as diversas falências da pobreza é a seguinte: 'Justiça é o ordenamento social que permite a cada membro cobrir suas necessidades e manter abertas suas opções de projeto de vida' (...) Não haverá uma ordem social justa na medida em que persistam segmentos sociais que não conseguem solucionar suas necessidades básicas, porquanto uma das tarefas essenciais de toda a sociedade é coordenar esforços para que todos os seus membros solucionem seus requerimentos de um modo que não poderiam fazê-lo individualmente" 20 (p. 70).
É mister que as necessidades legítimas sejam minimamente satisfeitas - de acordo com os anseios do próprio titular da existência 22 -, devendo-se evitar, cabalmente, que os recursos sejam desperdiçados com caprichos e condutas questionáveis, em relação à promoção, prevenção e restabelecimento da saúde e da qualidade de vida. Torna-se possível, na tessitura deste horizonte, apreciar a situação brasileira no âmago da discussão em curso. É fato reconhecido que há um progressivo e acentuado envelhecimento da população no país, abrindo a perspectiva de que um maior contingente de pessoas cheguem à senectude, tornando-se mais suscetíveis às moléstias crônicas - como as neoplasias - e, por conseguinte, a um processo de morrer, em tese, mais "prolongado" e sujeito à intervenção terapêutica de alta complexidade e custo 35 . Um emprego consciencioso e bem planejado dos recursos, capaz de contemplar estes meandros, deve ser a tônica da gerência em saúde, cabendo uma reflexão sobre a irresponsabilidade de se disponibilizar recursos já tão escassos para a manutenção de enfermos sem reais possibilidades de restabelecimento da saúde e de um adequado nível de vida, submetendo-os a um processo de morrer doloroso, angustiante, desnecessário e caro. Uma sociedade como a brasileira poderia arcar com este ônus? Provavelmente não, sobretudo se é vislumbrado que os doentes com exíguas possibilidades de recuperação - e que são $a r$ rastados para o calvário da distanásia - podem ocupar leitos úteis a pacientes com grandes chances de restabelecimento. Percebe-se, assim, que nesta postura, além dos absurdos já delineados, encontra-se também embutida a possibilidade de que um maior porcentual da população seja excluído da adequada assistência à saúde 32 , aguçando injustiças em uma nítida retroalimentação de desigualdades 36 . Sob este foco torna-se claro que o debate sobre a bioética do fim da vida, longe de ser uma questão apenas relativa ao indivíduo - aquele que morre -, apresenta uma importantíssima interface no âmbito da saúde pública.

Um equacionamento das questões sobre o fim da vida em termos do seu impacto sobre a sociedade, pode ser encontrado no diálogo $A$ República do filósofo grego Platão ${ }^{37}$. No Livro III dessa obra é elaborada uma censura aberta ao emprego da arte médica como forma de prolongar a vida, caso o enfermo esteja acometido por moléstia incurável. Para isso, utiliza uma bela e coesa argumentação, a qual se mantém ainda, de certa forma, extremamente atual, no sentido de se negar a morte no bojo de um prolongamento da vida a todo custo, o 
que se coloca em rota de colisão com a própria condição de finitude do homem. Nesse aspecto, uma análise um pouco mais detalhada sobre as ponderações presentes no terceiro livro de A República, poderá trazer relevantes subsídios teóricos às reflexões sobre os problemas relativos à obstinação terapêutica - distanásia.

\section{Livro III de A República: uma crítica à obstinação terapêutica}

Platão é, indubitavelmente, um dos filósofos mais importantes na história do Ocidente e, ao lado de Aristóteles, é considerado um expoente maior do pensamento na Antigüidade. Como um homem atento ao seu próprio tempo, Platão demonstrou preocupação com vários aspectos da vida espiritual grega, elaborando reflexões sobre a arte, a política, a matemática, a natureza e a medicina, entre outros assuntos 38. Em relação a esta última há inúmeras referências no pensamento platônico, podendo-se comentar como pontos importantes:

- A preocupação com o tratamento para as mais diferentes moléstias do homem - como o exposto em diálogos como o Cármides 38,39, o Fedro 41 e A República 37 , nos quais Platão expõe suas idéias acerca da terapia pela palavra; neste caso, as palavras são phármakon, no duplo sentido que o termo encerra: "veneno" e "remédio"; nas mãos do sofista são um tóxico mortal, mas, quando usadas pelo filósofo, podem se constituir em um profícuo bálsamo terapêutico - como o estabelecido no passo $270 \mathrm{~b}$ do Fedro: "[Sócrates] A medicina está no mesmo caso da retórica. [Fedro] Como assim? [Sócrates] Em ambas terás de analisar a natureza: na primeira, a do corpo; na outra, a da alma, se quiseres vencer a rotina e a experiência para alcançar a arte. No caso do corpo, a fim de deixálo forte e saudável, graças à alimentação e aos remédios; no da alma, por meio do ensino e de instituições legais, comunicar-lhe convicções e a virtude com que pretendes adorná-la [grifo nosso]" 41 (p. 70).

É exatamente nesse sentido que Platão qualifica a filosofia como uma genuína medicina da alma;

- A tomada do método hipocrático como paradigma para a dialética - no passo $270 \mathrm{c}$-d do Fedro 42; do erudito ateniense provém o testemunho antigo mais famoso sobre o Hipócrates histórico 43 .

- O fecundo trabalho de fisiologia e fisiopatologia realizado no diálogo Timeu 44, no qual há descrição das funções - nos estados de saúde e doença - de vários órgãos, são igualmente tecidas considerações sobre a composição íntima do corpo humano, o qual teria sua matéria redutível a triângulos passíveis de rearranjos, fato este com grandes implicações sobre a durabilidade física - leia-se também finitude - do homem 44,45 .

O alcance curativo da medicina é, para Platão, intimamente relacionado às causas e à história natural das enfermidades, bem como à constituição daquele que adoece. Em relação a estes aspectos tem importância capital o repertório de triângulos que compõe a intimidade do corpo humano, conforme as discussões presentes no diálogo Timeu. Cada pessoa ao nascer detém uma quantidade e arranjo de seus triângulos, os quais facultam um tempo de vida esperado e que não tem como ser prorrogado 44,45. Assim também são as doenças: elas têm um curso próprio - uma história natural -, segundo o qual o tempo de sua duração e o desenlace encontram-se preestabelecidos. Assim, nas palavras do próprio filósofo: "de regra, $a$ constituição das doenças apresenta alguma semelhança com a dos seres vivos, pois a composição destas condiciona uma duração regulada para a espécie em geral, nascendo cada pessoa com o tempo de vida fixado pelo destino, exceção feita para os acidentes inevitáveis de origem externa, pois desde o nascimento os triângulos de qualquer ser vivo se conglutinam de maneira que possam resistir até um determinado limite, além do qual ninguém consegue prolongar a vida. O mesmo se passa com a constituição das doenças" 45 (p. 100).

Há um determinismo inerente à constituição humana e ao desenrolar da doença, o qual torna limitado o alcance dos tratamentos prescritos. Na continuação deste mesmo passo do Timeu, Platão critica o uso de medicamentos para a contenção de doenças leves - as quais devem ser deixadas livres para seguir seu próprio curso -, enfatizando que os fármacos devem ser empregados apenas nos casos "mais graves", ou seja, naqueles em que há "grande perigo" para o doente 45 . As moléstias não devem, assim, ser irritadas com o uso de remédios, o que traz mais prejuízos que benefícios para aquele que sofre. Ainda mais, se a enfermidade for incurável - ou seja, mortal -, não deve ser prolongada a vida "artificialmente" por meio de modalidades terapêuticas - aqui, não restritas aos fármacos, mas também às práticas como a dieta e a ginástica - de acordo com o exposto em A República: "[Sócrates] (...) Heródico, que era mestre de ginástica, tornou-se enfermeiro, e, misturando o exercício básico com a medicina, atormentou-se primeiro e acima de tudo a si mesmo, e depois a muitos ou- 
tros. [Glauco] Como assim? - Perguntou ele. [Sócrates] Dilatando a sua própria morte - respondi eu. Acompanhando passo a passo a sua doença, que era mortal, sem ser, ao que parece, capaz de se curar, atravessou a vida a tratar-se, sem se ocupar de mais nada, estafando-se a ver que não se desviasse da dieta habitual, custando-lhe a morrer, devido ao seu saber, até que atingiu a velhice [grifo nosso]" 37 (p. 141).

Nesta passagem, Platão renega a atuação de Heródico, o qual adotou um "combinado" de ginástica e dieta para protelar sua moléstia incurável. Para isso utiliza o seu saber, ou seja, explicita-se aqui um uso no mínimo criticável para não dizer reprovável - de determinadas técnicas para perpetuar a sua vida que já se esvai. Este emprego equivocado do seu saber acabou por "atormentar" a si mesmo e a outros, no contexto de um vagar pela vida doente - subentendendo-se aqui que tenha sofrido e feito sofrer com isto. Neste sentido, seria muito mais pertinente se declinar em buscar, de forma "ensandecida", o tratamento da moléstia, uma vez que a morte, no caso de doenças incuráveis, pode ser muito mais redentora que algoz: “(...) se o seu corpo [do homem atingido por enfermidade mortal] não é capaz de resistir, a morte liberta-o de dificuldades [grifo nosso]" 37 (p. 142).

A opção pela morte pode ser mais razoável nestas circunstâncias, as quais se referem a moléstias não passíveis de cura. A indagação que se impõe é: seria esta uma vida que vale a pena ser vivida? Para Platão provavelmente não, uma vez que no bojo desta mesma passagem é feito o seguinte comentário: “(...) a ninguém é dado vagar para passar a vida doente, a tratar-se. $O$ ridículo desta situação, sentimo-lo nos artífices, mas não o sentimos nos ricos e nos que aparentam ser felizes" 37 (p. 145).

Torna-se claro neste excerto uma legítima preocupação política. Isso não poderia ser diferente, uma vez que em A República a questão proposta é "o que é a justiça?", e quais as suas implicações na organização da sociedade ( $p o ́$ $l i s=$ cidade-estado). Nesse diálogo, que transcorre entre Sócrates, Polemarco, Trasímaco, Glauco e Adimanto - estes dois últimos irmãos de Platão - é discutido tal conceito, o qual é aplicável em termos individuais e coletivos, com vistas à construção de uma pólis - e de uma sociedade - mais justas.

Neste sentido, um dos aspectos de relevância é o impacto negativo desses "moribundos" que "dilatam" o processo de morrer - na organização da cidade. Como a sociedade poderia mantê-los sem que trabalhassem? Eis aqui, em alguma medida, um problema com interface pública. E, neste caso, a referência é diáfana: para aquele que ganha a vida com o próprio esforço - o artesão - torna-se impossível arrastar-se pela existência a prorrogar seu tempo de vida - com dietas e ginástica -, conduta que subtrairia a possibilidade de trabalhar "para seu sustento", o de sua família, bem como para o bem da pólis. Para aqueles que são ricos a situação não é tão explícita, no entender de Platão: “ao passo que quem é rico, como dizíamos, não tem nenhuma ocupação premente dessa espécie, de que possa ser forçado a abster-se, sem que a vida se lhe torne impossivel" 37 (p. 143).

A vida tornar-se impossível diz respeito, ao que parece, mais propriamente à possibilidade de se manter - e cuidar dos seus -, o que tem grandes implicações sobre a viabilidade da pólis. Ao contrário, os abastados poderiam, em princípio, submeter-se a tais práticas, uma vez que sua condição econômica facultaria a opção por não trabalhar e produzir. Mas, o problema não se encerra tão simplesmente: mesmo os ricos têm graves conseqüências pela adoção de uma atitude afim ao realizado por Heródico. O prolongamento "artificial" da vida origina "fadiga cerebral", a qual dificulta o pensamento e embota a reflexão ${ }^{37}$. Assim, a doença é "cultivada", possibilitando que os doentes se tornem poliqueixosos e incapazes de exercer uma série de atividades. Esses problemas acabam por dificultar - e até mesmo impossibilitar - a atividade política dos homens: “(...) mas àquele que é incapaz de viver no círculo de ação que lhe foi adstrito, entendia que não se devia aplicar terapêtica, uma vez que nada lucrava com isso, nem o próprio, nem o Estado" 37 (p. 143).

Neste aspecto, mesmo o rico que não precisa trabalhar para subsistir, pode ter impedido o seu desempenho das funções legislativas e executivas na cidade. A vida, neste contexto, vale a pena ser vivida? A resposta é igualmente não, uma vez que, para o homem da Grécia clássica, a plenitude da existência é alcançada no fulcro da pólis, na atuação enquanto cidadão 46,47,48. Um grego de Atenas - cidade que experimentou o apogeu da democracia 49 - compreende que o alcance máximo de sua vida é obtido no exercício de direitos e deveres políticos, empreendendo debates na ágora, como o citado pelo próprio Platão na Carta Sétima: “outrora, em minha juventude, experimentei o que experimentam tantos jovens. Esperava entrar na política tão logo pudesse dispor de mim mes$m o " 50$ (p. 256).

Uma vida que não vale a pena ser vivida não deve ser protelada por meio de uma luta inclemente contra a morte. Referindo-se ao mito de Asclépio, Platão adverte que mesmo um deus foi punido por tal prática, como o mencionado 
em A República: "é assim que deve ser - respondi-embora não acreditem em nós os trágicos $e$ Píndaro, que dizem que Asclépio era um filho de Apolo, que se deixou persuadir pelo ouro a curar um homem rico que estava já para morrer, motivo por que foi fulminado [grifo nosso]" 37 (p. 145).

Assim, o "investimento" em indivíduos cuja doença é inexorável não obtém qualquer sustentação nas concepções do filósofo de Atenas, conceito que alberga importante correlação com o tratado hipocrático Da Arte, conforme o excerto a seguir: “[à medicina não cabe] tratar os doentes que são vencidos pelas enfermidades" 51 (p. 123).

Consoante o já referido, Platão, em A República, tem por objetivo precípuo fundamentar a construção da pólis - em íntima articulação com a discussão sobre a justiça -, ou seja, é perceptível uma preocupação genuinamente política e coletiva. A articulação tecida no próprio diálogo traz importantes aspectos relativos à organização da sociedade ideal, fortemente aristocrática, com a colocação de um homem bem preparado - o rei filósofo - como maestro e regente da pólis. Todavia, ainda que não esteja presente no diálogo a tão cara igualdade entre os homens - o que está fora da textura cultural helênica, sendo algo muito posterior, incipiente no cristianismo primitivo e consolidado na modernidade 52 -, o problema é colocado de forma tão clara em relação à vida que vale a pena ser vivida, que se pode recompor esta passagem nos termos hodiernos da preeminência do princípio da qualidade de vi$d a(\mathrm{PQV})$ sobre o princípio da sacralidade da vida (PSV), se o excerto é contextualizado no debate contemporâneo. Esta abordagem remete à questão aristotélica de que o bem ético se engendra em uma vida excelsa, a qual tem na eudaimonía (felicidade) sua excelência máxima 53. E o mais interessante é que, mesmo para um pensador fortemente aristocrata como Platão, não há diferença entre os homens (cidadãos) no que se refere à opção por deixar de existir, caso a vida não exiba um mínimo de qualidade - ou sentido - necessária à condição de homem e cidadão.

Outro aspecto que emerge com força diz respeito à dificuldade para que a pólis platônica de A República sustente, do ponto de vista econômico, as conseqüências de um prolongamento sem sentido da vida. E mais precisamente neste ponto, percebe-se a "atualidade" dos comentários do filósofo da Antigüidade em relação aos problemas de limitação de recursos já demarcados, os quais incrementam as discussões contemporâneas sobre a bioética do fim da vida. É claro que o subjacente as duas situações é distinto: na pólis é a questão da impossibilidade de produção - oriunda da "falta de tempo" e de "disposição" para se dedicar ao labor -, enquanto que no presente momento o grande obstáculo é a exigüidade dos recursos (o que, de todo modo, está também implícito na análise platônica). Mas, ainda assim, tanto em um quanto em outro caso, seria necessário que a coletividade deslocasse verbas para manter a vida destes homens "desenganados" - os antigos em suas casas, os de hoje nas UTIs - o que, dependendo do número de enfermos, pode inviabilizar a economia. Assim, a passagem é bastante ilustrativa no sentido de advertir sobre os problemas da obstinação terapêutica.

Parece bastante evidente que o meandro econômico não deva ser o único determinante das discussões éticas e bioéticas, sobretudo se entendido no sentido redutivo que a economia adquiriu no mundo contemporâneo - disjunta da ética, como o denunciado por Amartya Sen 54. Sem embargo, no que diz respeito à saúde pública, este "quesito" é de incontornável relevância, dada a já comentada limitação de recursos. Sobre este aspecto - tensão entre ética e economia - é pertinente comentar que: “(...) a saúde, embora não possa ser reduzida a mera mercadoria (o que seria uma tirania em termos walzerianos), tampouco pode ser encarada independente de seus custos, razão pela qual prática médica e gestão sanitária devem ser pensadas juntas e negociadas tendo em vista o objetivo da criação do consenso entre partes em conflito. Mas o problema, neste caso, é como fazer com que as políticas de saúde sejam "inclusivas" e não excludentes, ou seja, determinadas a partir de um olhar positivo da questão polêmica dos recursos finitos ou escassos" 55 (p. 80).

Obviamente, esta discussão não é imediatamente clara em A República - afinal, não se pretende o estabelecimento de uma extensão linear entre o pensamento do ateniense e a bioética do fim da vida, mas, outrossim, a recolocação hodierna da questão platônica -, mas pode-se considerá-la de algum modo conceitualmente afim, conforme tentou-se demarcar até aqui. Ademais, a interface da saúde pública com a bioética não se limita, obviamente, às questões de alocação de recursos, podendo-se mencionar problemas como a eqüidade, a justiça, o acesso aos serviços de saúde, entre tantos outros pontos 21,36,56,57, delimitando um fecundo panorama de interseções. Estas questões não foram tacitamente contempladas para que não se fugisse da linha mestra de argumentação presentemente desenvolvida. Deste modo, guardadas as devidas limitações, o filósofo de 
Atenas permite uma leitura sobre a importância de também se levar em consideração os fatores de ordem econômica - no caso do artesão - como mais um dos elementos para uma discussão laica e plural sobre a obstinação terapêutica.

\section{Ponderações finais}

As questões sobre o processo de morrer têm origens muito antigas, como se pôde perceber pela análise do Livro III de A República - o próprio Sócrates, conta Platão, ensinava que no propósito da filosofia está o aprender a morrer. É interessante como o ateniense, um filósofo que viveu há mais de 2.400 anos, articula tão belamente argumentos contra a obstinação terapêutica, nos aspectos relacionados ao indivíduo que perece mas, igualmente, em sua relevância como questão pública. Em linhas gerais, ter-se-ia:

- A inexorabilidade de determinadas moléstias - como o discutido no Timeu - para as quais tornar-se-ia inútil a adoção desenfreada dos diferentes métodos de tratamento; sobre este aspecto, na atualidade, pode se remontar a determinadas enfermidades degenerativas que, quando diagnosticadas, encontrar-se-iam já em fase terminal, sendo portanto incuráveis; - O grande sofrimento imputado pela obstinação terapêutica, tanto para o que a vive quanto para aqueles que lhe são próximos;

- A questão das dificuldades da pólis em manter esses pacientes lançados no processo de morrer, uma vez que, além de não produzir, vão necessitar que seu sustento caiba à sociedade, podendo se tornar inviável tal status quo;

- Uma possibilidade de se pensar, com o auxílio da interrogação construída por Platão, a subsunção do PSV pelo PQV, na medida em que o enfermo, atormentado e consumido pela luta insana contra suas mazelas, abdica da vida pública como cidadão, tornando sua existência sem sentido.

Em todas as situações pontuadas baseando-se na obra platônica, o ser humano doente torna-se um "estorvo" para si mesmo, seus semelhantes e para a pólis como um todo. Poderse-ia articular os quatro pontos arrolados em torno da pergunta já colocada: por que tratar obstinadamente um enfermo cuja vida não vale a pena ser vivida? Por sua vez esta indagação remete, ato contínuo, à questão: o que é uma vida que vale a pena ser vivida? Eis duas colocações que, por si mesmas, demandariam uma investigação profunda. No transcorrer deste breve ensaio procurou-se demarcar que Platão dá exemplos, contextualizados em seu tempo, de vidas que já não valiam a pena ser vividas e para as quais a morte significaria libertação. Este é o ponto.

Parece igualmente manifesto que o panorama é diferente - afinal, não existia qualquer "coisa" similar a uma UTI no século IV a.C.! Todavia, os aspectos ressaltados por Platão nas passagens estudadas sugerem um mesmo tipo de inquirição subjacente: o quão pode ser deletério o prolongamento inútil da vida para um indivíduo já com a morte anunciada, tanto nos aspectos de foro íntimo, quanto nas relações com as pessoas próximas e nas implicações para com a sociedade. Não é exatamente este o coração do debate bioético sobre o fim da vida? Não seria factível discutir a distanásia a partir de uma retomada dos problemas levantados pelo ateniense?

A dúvida, como apresentada, tem relevantes pontos de contato com os problemas enfrentados pela bioética do fim da vida, nestes primórdios do século XXI. Estas conjecturas tornam-se, assim, um modelar convite à reflexão. Há que se debruçar sobre o problema representado pela obstinação terapêutica, para que a tão arraigada prática de luta incessante contra a morte - muito familiar na medicina contemporânea - seja revista com a maior urgência 23, sobretudo comparando-a com as mortes evitáveis. Uma ampla discussão no âmbito dos profissionais de saúde e da sociedade civil seria altamente desejável pelas possibilidades de aprimoramento no trato destas ponderações. Afinal, o médico não pode se colocar como um gladiador contra a morte 58 - sob este prisma, já se entra na "luta" com todo o ônus da derrota, uma vez que o fim é inexorável mas sim como um profissional, detentor de uma arte à moda hipocrática, devendo buscar o restabelecimento da saúde para aquele que dela se encontra privado, sempre que possível. Entretanto, este possível está aberto, dinâmico, dependendo dos avanços da arte-técnica-ciência médica. Tampouco os homens que estão com uma lenta morte em curso devem se colocar como um objeto dessa luta, arena na qual o médico, usando seu "arsenal terapêutico", irá medir forças com a morte. Com que preço? Com quais recursos? Os mesmos capazes de reduzir agudamente a mortalidade infantil em um país como o Brasil? A mentalidade precisa ser revista, a indisposição hodierna para com a morte necessita ser desconstruída. É preciso filosofar... E aprender a morrer, como queria Michel de Montaigne 5.

Filosofar? Há íntimas e estreitas relações entre a filosofia e a medicina, estando a bioéti- 
ca aí como testemunho disto. É assim, pois, que um filósofo da envergadura de Platão, se propôs a pensar, de modo fecundo e polêmico, uma série de aspectos da medicina sua contemporânea. E esta perspectiva é do maior interesse: a disposição para se refletir sobre a arte médica, suas doutrinas e métodos, o alcance de sua técnica, os seus liames morais, a radicalidade de sua dimensão humana, permitindo uma medicina apreensível como ciência humana. Procedendo assim, à moda platônica mas também hipocrática, como o efetuado no tratado Da Arte - torna-se provável uma conciliação entre a biotecnociência e a ética, minimizando o descaso e a distância - com aprofundamento da compaixão - em relação ao homem que morre. E, exatamente no télos deste fazer médico mais voltado para o todo - como desejava Platão -, pode-se almejar um novo paradigma, segundo o qual aqueles que abraçam o legado de Hipócrates regressem à condição de menos técnicos em medicina e mais médicos de homens, almas e corações.

\section{Resumo}

Discutir os aspectos bioéticos da obstinação terapêutica, tendo em vista algumas de suas interseções no âmbito da saúde pública, é o escopo do presente artigo. Partindo-se de uma delimitação da finitude no bojo do debate filosófico e bioético sobre o fim da vida, intentou-se confrontar as críticas contemporâneas à distanásia com o pensamento do filósofo Platão (427-347 a.C.), pensador que desenvolveu uта arguta reflexão sobre os mais diferentes aspectos da medicina do seu tempo. Desta feita, buscou-se a exploração de novos referenciais teóricos, capazes de nortear as discussões relativas a este crucial problema, cujas implicações são decisivas no âmbito da saúde e da vida.

Bioética; Futilidade Médica; Morte; Saúde Pública

\section{Colaboradores}

R. Siqueira-Batista contribuiu nos aspectos relativos à filosofia grega. F. R. Schramm proporcionou o diálogo do pensamento platônico com a filosofia contemporânea e a bioética.

\section{Referências}

1. Dastur F. A morte. Ensaio sobre a finitude. Rio de Janeiro: Editora Difel; 2002.

2. Homero. Odisséia. 2a Ed. São Paulo: Edusp; 1996.

3. Siqueira-Batista R. Deuses e homens. São Paulo: Landy; 2003.

4. Zaidhaft S. Morte e formação médica. Rio de Janeiro: Jorge Zahar Editor; 1997.

5. Montaigne M. Ensaios. São Paulo: Nova Cultural; 2000.

6. Heidegger M. Être et temps. Paris: Gallimard; 1986.

7. Spinosa B. Ethic. Paris: Gallimard; 1954.

8. Hegel GWF. Fenomenologia do espírito. Petrópolis: Editora Vozes; 1992.

9. Sartre J-P. O ser e o nada. Ensaio de fenomenologia ontológica. 2a Ed. Petrópolis: Editora Vozes; 1997.

10. Nietzsche FW. A Gaia ciência. São Paulo: Hemus; 1981.

11. Schramm FR. Paradigma biotecnocientífico e paradigma bioético. In: Oda L, organizadora. Biosafety of transgenic organism in human health products. Rio de Janeiro: Fundação Oswaldo Cruz; 1996. p. 109-27.

12. Mori M. A Bioética: sua natureza e história. Humanidades 1994; 9:333-41. 
13. Potter VR. Bioethics, science of survival. Biology and Medicine 1970; 14:153-73.

14. Potter VR. Bioethics: bridge of the future. Englewood: Prentice-Hall; 1971.

15. Almeida JLT, Schramm FR. Transição paradigmática, metamorfose da ética médica e emergência da bioética? Cad Saúde Pública 1999; 15 Suppl 1:15-25.

16. Schramm FR. Niilismo tecnocientífico, holismo moral e a 'bioética global' de V. R. Potter. Hist Ciênc Saúde 1997; 4:95-115.

17. Schramm FR. Bioética e comunicação em oncologia. Rev Bras Cancerol 2001; 47:25-32.

18. Kottow M. Introdución a la Bioética. Santiago: Universitária; 1995.

19. Cordeiro H. Descentralização, universalidade e eqüidade nas reformas da saúde. Ciênc Saúde Colet 2001; 6:319-28.

20. Kottow M. Bioética e política de recurso em saúde. In: Garrafa V, Costa SIF, organizadores. Bioética no século XXI. Brasília: Universidade de Brasília; 2000. p. 67-75.

21. Ribeiro CDM. "Cultura dos limites", justiça sanitária e alocação de recursos: argumentações racionais acerca dos conflitos morais em medicina intensiva neonatal, do ponto de vista dos profissionais intensivistas [Tese de Doutorado]. Rio de Janeiro: Escola Nacional de Saúde Pública, Fundação Oswaldo Cruz; 2002.

22. Sen A. ¿Por qué la equidade en salud? Rev Panam Salud Pública 2002; 11:302-9.

23. Pessini L. Distanásia. Até quando prolongar a vida? São Paulo: São Camilo/Loyola; 2001.

24. Barrêtto FJT. A morte e o morrer. A assistência ao doente terminal. In: Mello Filho J, organizador. Psicossomática hoje. Porto Alegre: Artes Médicas; 1992. p. 287-98.

25. Siqueira-Batista R. O médico e a morte: revendo o Asclépio que subsiste em nós. Jornal do Conselho Regional de Medicina 2001; 14:4.

26. Schramm FR. Morte e finitude em nossa sociedade: implicações no ensino dos cuidados paliativos. Rev Bras Cancerol 2002; 48:17-20.

27. Quintana AM, Cecim PS, Henn CG. O preparo para lidar com a morte na formação do profissional de medicina. Rev Bras Educ Méd 2002; 26:204-10.

28. Schramm FR. Por qué la definición de muerte no sirve para legitimar moralmente la eutanasia y el suicidio asistido? Perspectivas Bioéticas 2001; 6:43-54

29. Siqueira-Batista R. O médico diante da morte: perspectivas de discussão ética com base na filosofia de Immanuel Kant. Revista da Faculdade de Medicina de Teresópolis 2001; 3:18-22.

30. Suetônio. A vida dos doze Césares. 2a Ed. São Paulo: Prestígio; 2002.

31. Neukamp F. Zum problem der euthanasie. Der Gerichtssaal 1937; 109:403.

32. Martin LM. Eutanásia e distanásia. In: Costa SIF, organizador. Iniciação à bioética. Brasília: Conselho Federal de Medicina; 1998. p. 171-92.

33. Pessini L. Distanásia: até quando investir sem agredir? Bioética 1996; 4:31-43.

34. Gafo JL. Euthanasia: el derecho a una muerte humana. Madrid: Ediciones Temas de Hoy; 1990.

35. Lachs J. Dying old as a social problem. In: McGee
G, editor. Pragmatic bioethics. Nashville/London: Vanderbilt University Press; 1994. p. 194-203.

36. Wagstaff A. Pobreza y desigualdades en el sector de la salud. Rev Panam Salud Pública 2002; 11:316-26.

37. Platão. A República. Lisboa: Fundação Calouste Gulbenkian; 1987.

38. Cornford FM. Antes e depois de Sócrates. São Paulo: Martins Fontes; 2001.

39. Platão. Cármides. Coimbra: I.N.I.C.; 1988.

40. Coolidge Jr FP. The relation of philosophy to $\Sigma \omega \phi \rho о \sigma u ́ v \eta$ : Zalmoxian medicine in Plato's Charmides. Ancient Philosophy 1993; 13:23-36.

41. Platão. Fédro. Porto Alegre: Editora Globo; 1950.

42. Cambiano G. Dialettica, medicina, retorica nel Fedro platonico. Rivista di Filosofia 1966; 57:284305.

43. Frias IM. Platão, leitor de Hipócrates. Londrina: Editora da UEL; 2001.

44. Platão. Timée. Paris: Belles Lettres; 1956.

45. Platão. Timeu. Belém: Editora da UFPA; 1977.

46. Cardoso C. A cidade-estado antiga. São Paulo: Editora Ática; 1985.

47. Detienne M. Os mestres da verdade na Grécia arcaica. Rio de Janeiro: Jorge Zahar; 1988.

48. Vernant J-P. Entre mythe et politique. Paris: Sueil; 1996.

49. Mossé C. Atenas: a história de uma democracia. 3ạ Ed. Brasília: Editora UNB; 1997.

50. Platão. Cartas. Belém: Editora da UFPA; 1974.

51. Hippocrates. The art. Cambridge: Harvard University Press; 1992.

52. Dallari SG. A bioética e a saúde pública. In: Costa SIF, organizador). Iniciação à bioética Brasília: Conselho Federal de Medicina; 1998. p. 171-92.

53. Aristóteles. Ética a Nicômaco. São Paulo: Abril Cultural; 1972.

54. Sen A. Desigualdade reexaminada. Rio de Janeiro: Record; 2001.

55. Schramm FR. A difícil dialética entre economia e ética. Rev Bras Educ Méd 2000; 24:77-81.

56. Schramm FR, Kottow M. Princípios bioéticos en salud pública: limitaciones y propuestas. Cad Saúde Pública 2001; 17:949-56.

57. Schütz G. Quando o "igual tratamento" acaba em injustiça. Um paradoxo bioético das políticas sanitárias universalistas de alocação de recursos [Dissertação de Mestrado]. Rio de Janeiro: Escola Nacional de Saúde Pública, Fundação Oswaldo Cruz; 2002.

58. Siqueira-Batista R, Siqueira-Batista R. De como filosofar é aprender a morrer. O pensamento de Michel de Montaigne como pressuposto na discussão sobre a morte e o processo de morrer na prática médica. Cad Saúde Colet (Rio J) 2002; 10:9-18.

Recebido em 05/Jun/2003

Versão final reapresentada em 16/Fev/2004

Aprovado em 01/Mar/2004 